\title{
El imaginario racial y la literatura estadounidense
}

\section{Racial imaginary and US literature}

\author{
Regina de las Mercedes Constantin Agramonte $\square$
}

Universidad de La Habana, La Habana,Cuba

Recibido: 16/06/2020

Revisado: 26/07/2020

Aceptado: 20/09/2020

Publicado: 16/12/2020

\section{RESUMEN}

El objeto de estudio de este trabajo es el imaginario racial en el discurso literario estadounidense. El objetivo es determinar cómo el discurso de actantes ilocutivos y sujetos valoradores femeninos negros refleja el imaginario racial del sujeto de la enunciación. Se desarrolla la base teórica de la investigación, que incluye el discurso, el Análisis Crítico del Discurso, los imaginarios y la ideología. Para ejecutar las tareas se utilizaron los métodos de revisión de la literatura especializada, el histórico-lógico, el inductivo-deductivo, análisis literario, Análisis Crítico del Discurso, y analítico-sintético. Se estudiaron varias obras de la literatura estadounidense con temática racial escritas por autores blancos y negros para entender sobre las dificultades para escribir sobre el "otro". Finalmente, se escogió como muestra el discurso de sujetos valoradores femeninos negros de la novela The Help, que ha sido objeto de controversia desde su publicación. Se realizó un análisis dimensional que demostró que efectivamente el imaginario racial tiene un gran impacto en la descripción de los personajes, aunque la novela comparte elementos positivos con algunas obras de la literatura afroamericana. Palabras clave: Análisis Crítico del Discurso, ideología, imaginario racial, literatura estadounidense.

\section{ABSTRACT}

The racial imaginary in the United States' literary discourse is the object of study of this research, which is aiming at determining how the discourse of ilocutive agents, who are black female valuating subjects, reflects the racial imaginary of the author as a subject of the enunciation. Theory involving discourse, Critical Discourse Analysis, imaginaries and ideology was presented in the research. The methodology included a literary review, a literary analysis, a Critical Discourse Analysis, the historical-logical, the inductive-deductive and analytic-synthetic methods. Several US novels dealing with race and written by black and white authors were analyzed in order to understand the difficulties in writing about the "other". Finally, The Help was selected for the discourse analysis of black female valuating subjects due to the controversy this novel generated since its release. A dimensional analysis demonstrated that even though the racial imaginary has indeed an impact on the portrayal of the charac- 
ters, this novel also has positive characteristics present in some African-American works. Keywords: Critical Discourse Analysis, ideology, racial imaginary, US literature.

\section{INTRODUCCIÓN}

Definir el discurso resulta una tarea compleja debido a que está relacionado con fenómenos complejos que representan disciplinas independientes como el lenguaje, la comunicación, la cultura, y la interacción. Sin embargo, la definición que se utilizará en esta investigación es la brindada por Ayala (2004) donde plantea que:

El discurso es una forma de práctica social y el uso de la lengua con relación a las formaciones políticas, sociales y culturales. Por este motivo el discurso se refleja en el orden social y da forma al mismo, al igual que influye en la interacción del individuo con la sociedad (Ayala, 2004, p.19).

Esta definición incluye las tres dimensiones del discurso identificadas por Van Dijk (1993): el uso del lenguaje, la comunicación de creencias y la interacción en situaciones sociales.

Creencias y opiniones están enraizadas en el discurso y constituyen el motor impulsor del proceso de comunicación, durante el cual los que interactúan aceptan, rechazan y se retroalimentan de lo que se plantea. Esas creencias y opiniones no están aisladas, forman parte de un imaginario común a grupos dentro de la sociedad.

Morris y Nerlich (2015) plantean que el imaginario surgió como término en los años $50 \mathrm{y}$ 60 del siglo XX cuando Paul Cardán, seudónimo de Cornelius Castoriadis, lo utilizó en una crítica a la ideología soviética; sin embargo, anteriormente otros intelectuales habían explorado la conciencia colectiva y su poder social. Emile Durkheim, sociólogo del siglo XIX, consideraba que la conciencia colectiva era la totalidad de creencias y de sentimientos comunes a los miembros de la misma socie dad y era lo que la mantenía unida (Morris y Nerlich, 2015). Ferdinand de Saussure, según afirman Morris y Nerlich (2015), también exploró el lenguaje como parte de lo que hoy muchos intelectuales llaman imaginario colectiv o o social. Inspirado en la ideología de Immanuel Kant sobre la imaginación, en 1975 Cornelius Castoriadis publicó con su propio nombre L'Institution imaginaire de la société (La institución imaginaria de la sociedad), donde aseveró que la sociedad solo existía porque era imaginada colectivamente de cierta manera (Morris y Nerlich, 2015).

Intelectuales (Gaceta Sanitaria, 2010) coinciden en que los imaginarios son un conjunto de valores, instituciones, leyes, símbolos y mitos comunes a un grupo dentro de la sociedad en un momento dado. García Canclini profundiza la definición de imaginario cuando plantea que "lo imaginario remite a un campo de imágenes diferenciadas de lo empíricamente observable" (en Lindón, 2007, p.90). El autor aclara que estas imágenes son elaboraciones simbólicas no solo de lo que podemos percibir, sino de lo que nos causa temor o nos gustaría que fuera real.

En esta investigación se considera entonces que los imaginarios ${ }^{1}$ son:

Universos de valores, pensamientos, símbolos, mitos, instituciones, e ideologías que son comunes a un grupo social en un contexto dado. 
Esta situación influye en la producción del conocimiento, pues un mismo fenómeno o proceso puede tener diferentes interpretaciones, según el contexto y la posición de los grupos dentro de la sociedad. De acuerdo con Cabrera (2004), esta posición no es más que la identidad colectiva, conformada por las creencias compartidas que hacen que los miembros de un grupo social tengan igual visión de sí en contraposición con aquellos que no pertenezcan al grupo. Esta identidad depende de propiedades autodefinidas fundamentales, relacionadas con la discriminación del otro: el origen, la apariencia, la etnicidad, el género, el lenguaje, la religión, entre otros. Por lo tanto, los imaginarios sociales determinan las relaciones de los miembros de la sociedad, rigen su vida social y legitiman sus prácticas sociales. Las significaciones imaginarias sociales instituyen, justifican o critican un orden social.

Ese es un pensamiento que remite a los estudios de Van Dijk sobre la ideología. Desde el punto de vista filosófico, Marx (en Ambriz-Arévalo, 2015) definió la ideología como el sistema de representaciones del mundo (políticas, religiosas, filosóficas, morales, judiciales y estéticas) que el hombre se hace de la realidad, ligadas a las condiciones materiales de existencia, las condiciones reales en las que se desenvuelve la vida humana. La ideología determina lo que somos como miembros de un grupo.

Sin embargo, desde el punto de vista lingüístico, VanDijk(1993,1998)definelasideologíascomo:

Pensamientos y creencias que reflejan y protegen los objetivos básicos, los intereses y valores de los grupos. Las ideologías son la base de las representaciones sociales compartidas por los miembros de un grupo, enraizadas en creencia- nerales de toda una sociedad o cultura.

Las ideologías representan la piedra angular del juicio y la acción. Ellas legitiman las acciones de los grupos sociales y organizan sus actitudes con respecto a problemas sociales relevantes. Estos miembros comparten opiniones sobre experiencias y conflictos comunes, que conforman las representaciones sociales. Además, estos miembros se sienten identificados con su grupo debido a los sentimientos de pertenencia, su identidad social.

Cuando la acción social y la interacción se coordinan para defender los intereses grupales y existe un sentido de identificación con objetivos comunes, todas las condiciones están creadas para la formación de grupos ideológicos. Muchos grupos ideológicos tienden a organizar partidos u organizaciones no gubernamentales, que desempeñan un papel relevante en la incorporación de nuevos miembros, el establecimiento de los objetivos y la formulación de normas y principios (ideologías). Por lo tanto, los grupos dominantes desarrollarán una ideología que los ayude a mantener su dominación, mientras que los dominados pueden crear una ideología que sirva como base para sus prácticas y discursos de resistencia.

Las ideologías son las superestructuras del imaginario que enmarcan los elementos de la cognición social que identificarán y diferenciarán a los miembros del grupo social, como miembros de este y no de otro. Las ideologías están constituidas por selecciones de valores socioculturales relevantes y tienen la función de servir a los intereses de los grupos. Las ideologías como controladoras de las prácticas sociales estarán presentes en el discurso de los individuos y, por lo tanto, en el discurso literario.

Como el discurso es partícipe en fenómenos sociales complejos, resulta necesario em- 
plear una ciencia interdisciplinaria. Ese es el caso del análisis del discurso, que trata de explicar las relaciones que existen entre las tres dimensiones anteriormente mencionadas. El análisis del discurso se orienta a las interrelaciones del lenguaje con la sociedad y trasciende el análisis de la sintaxis del lenguaje, puesto que se enfoca en los procesos mediante los cuales se construye y mantiene el mundo social (Phillips \& Hardy, 2002, p.11). Entonces, con esta ciencia se pueden analizar las dimensiones ideológicas del uso del lenguaje (Pêcheux en Wodak, 2001, p.23).

En la década de 1990, los estudios realizados confirmaron la necesidad de incluir una dimensión crítica en el análisis del discurso para poder investigar sobre problemas sociales como la desigualdad y el abuso de poder, temas que se convirtieron en el centro de atención de los investigadores. El Análisis Crítico del Discurso considera al lenguaje una forma de práctica social y tiene como objetivo esclarecer los puntos de conexión entre las estructuras sociales, el discurso y las prácticas sociales. De esta forma el Análisis Crítico del Discurso explora la relación entre las prácticas discursivas y las estructuras socioculturales e investiga críticamente la desigualdad social y su expresión y legitimación mediante el lenguaje (Fairclough en Wodak, 2001).

La definición de Análisis Crítico del Discurso de Van Dijk que será utilizada en esta investigación plantea que:

Esun tipo de investigación analítica sobre el discurso que estudia primariamente el modo en que el abuso de poder social, el dominio y la desigualdad son practicados, reproducidos y ocasionalmente combatidos por los textos y el habla en el contexto social y político (1999, p.23).
Los analistas ven el lenguaje como un medio de dominación y de fuerza social que legitima las relaciones de poder (Habermas en Wodak \& Meyer, 2008). Como el Análisis Crítico del Discurso examina la reproducción y el mantenimiento del poder y de la dominación dentro de contextos históricos y sociopolíticos concretos, es necesario definir esos términos.

Según Blau y Emerson (en Wodak \& Meyer, 2008), el poder es inherente al intercambio social en cada interacción. Los psicólogos French y Raven (en Wodak \& Meyer, 2008) definen el poder como el resultado de recursos específicos empleados por actores individuales. Foucault y Guiddens (en Wodak \& Meyer, 2008) consideran que el poder es un elemento sistémico y constitutivo de la sociedad. Vidal (en Ayala, 2004) afirma que el poder es la capacidad de cambiar el comportamiento o la actitud de las personas de manera favorable a nuestros intereses personales. Fowler (en Ayala, 2004) incluye dentro de esta definición la idea de que no solo las personas sino también las instituciones pueden ejercer el control. Van Dijk (1993) concuerda con la afirmación de que para ejercer el poder es preciso tener el control para limitar la libertad de acción de los otros e influenciar sus mentes mediante la persuasión o la manipulación.

El poder social es la relación entre las instituciones o grupos poderosos y los que no lo son. Los grupos privilegiados, que tienen acceso a recursos socialmente valiosos como es el caso del conocimiento, la riqueza y el estatus, serán capaces de dominar las mentes de los que carecen de poder. Por este motivo el concepto de dominación está estrechamente relacionado al poder social. Este término hace referencia a formas ilegítimas e inaceptables de poder. La dominación puede ser reproducida de maneras sutiles en el discurso oral y escrito que aparenta ser natural y aceptable. 
Cuando los dominados aceptan la dominación y sus acciones favorecen a los grupos poderosos, estamos frente a la hegemonía (Van Dijk, 1993). Por lo tanto, las ideologías desempeñan un papel importante en el establecimiento y preservación de las relaciones de poder y la dominación. Las ideologías dominantes resultan neutrales y defienden creencias que se mantienen sin ser desafiadas por largo tiempo hasta que surgen grupos minoritarios con una ideología y un discurso de resistencia.

Ese fue el caso de grupos de mujeres afroamericanas en los Estados Unidos. Con el paso del tiempo, la resistencia de la mujer negra, surgida a partir de las injusticias durante el periodo de la esclavitud, comenzó a formar parte de su sabiduría, que permitió el desarrollo de su dignidad, fortaleza, independencia e imaginación. Como las mujeres negras trabajaron unidas en la búsqueda de su emancipación surgió la tradición de narrar historias donde se valoran experiencias vividas y concretas, así como germinó la hermandad y sentido de comunidad de las mujeres de descendencia africana (Hill Collins, 1990).

La experiencia afroamericana siempre ha sido un tema de interés en la literatura estadounidense. Aunque ha sido reflejada y analizada en obras que pertenecen a la literatura afroamericana, la experiencia de los negros en Estados Unidos ha atraído a autores de la nación que no tienen descendencia africana. La escritura sobre temas raciales y la habilidad o el derecho que tienen algunos autores a escribir sobre el "otro" constituyen temas de controversia entre investigadores, escritores y audiencias. Por ese motivo muchas novelas famosas con protagonistas negros creados por escritores blancos han sido criticadas, tal es el caso de Uncle Tom's Cabin, The Adventures of Huckleberry Finn, y recientemente, The Help.
Durante el análisis de las complejidades sobre este tema se introduce el término imaginario racial que hace referencia a la forma en que la cultura imagina las oportunidades narrativas, los sentimientos y las situaciones, los temas y recursos estilísticos, las formas y las voces, disponibles para los personajes de diferentes razas y sus autores. El tema racial no solo afecta el contenido (narración, imágenes o estereotipos) sino también la forma (la gramática y la selección de las palabras) (Loffreda \& Rankine, 2015). Consecuentemente, el imaginario racial influye en el discurso literario.

Según el construccionismo social, el discurso contribuye a la creación de visiones del mundo, de las personas y de nosotros en consecuencia (Paltridge, 2015). El discurso y el contexto tienen un efecto sobre las identidades sociales y las relaciones. Cuando los escritores pasan trabajo con la selección de palabras exactas, también están lidiando con asunciones y valores que han estado ligados a esas expresiones, frases, o términos a lo largo de la historia. Por consiguiente, los escritores producen un discurso y como resultado obtenemos un texto permeado de valores e ideologías, que tienden a estar escondidas, no se mencionan abiertamente, y so reflexiones de realidades sociales y procesos que se oponen a ellas o contribuyen a su mantenimiento.

Escribir sobre cuestiones raciales sin expresar los prejuicios propios representa un reto para los autores. Los intelectuales que estudian el imaginario racial consideran que es un desafío hablar sobre raza sin mencionar la discriminación racial. Como resultado, la representación del otro se ve afectada por la identidad racial o la ausencia de identidad racial del autor.

Surgida de la posición desprivilegiada y de la falta de representación de la comunidad negra, 
la literatura afroamericana ha servido como un arma de resistencia y denuncia del sistema discriminatorio, además de brindar apoyo emocional y reflejar los retos diarios y las victorias. Los autores afroamericanos han tenido la difícil tarea de crear una obra artística de interés para una amplia audiencia, pero comprometida con la causa social, política y económica de la comunidad negra. Por ese motivo la literatura afroamericana ha sido erróneamente clasificada como literatura de protesta correspondiente a los "problemas de negros". No obstante, la misma categorización ha provocado la afirmación de que los autores negros son los únicos con el derecho o la competencia para escribir sobre la experiencia afroamericana.

Los autores blancos desde su posición privilegiada han escrito también sobre la experiencia afroamericana. Muchos de ellos han decidido hacerlo para condenar las injusticias sufridas por los estadounidenses negros y apoyar sus causas, como lo fue la abolicionista y la relacionada con los derechos civiles.Sin embargo, esa posición privilegiada, creada por cientos de años de opresión basada en ideologías dominantes, puede haber afectado su trabajo de reflejar a los afroamericanos. Según Llewellyn (2015), escribir a partir de su propio racismo interiorizado es un obstáculo que los escritores blancos deben superar para evitar la creación de personajes planos o excesivamente victimizados, que luego son criticados por la audiencia afroamericana.

Llewellyn (2015) también plantea que algunos escritores blancos que temen la reacción del público prefieren omitir el tema racial mientras que otros proclaman sentirse cómodos al tratar esa temática. Muchos utilizan bromas para asumir que existe una distancia entre la discriminación racial mostrada y las creencias actuales propias y de la audiencia, de esta for- ma se burlan del racismo de épocas pasadas o de los racistas actuales (Llewellyn, 2015). Como ubican el tema racial y el racismo en el pasado, estos autores no profundizan en estos temas de forma crítica, no hacen resistencia al status quo y convierten la opresión racial en una comedia que estimula una complacencia acrítica de la audiencia, con lo cual se reforzó durante un tiempo la creencia de que los días de dominación racial habían terminado en la sociedad estadounidense.

Por otra parte, existen autores que utilizan sentimiento racista para impactar a la audiencia. Aunque sus trabajos son defendidos como obras valientes y honestas por haber tratado la temática racial, también reciben críticas por contribuir a la continuación de la ideología racista. A menudo, de forma involuntaria perpetúan estereotipos y puntos de vista racistas cuando los utilizan en sus obras. Según Llewellyn (2015), esto puede ser el resultado de una falta de investigación de los principios e imágenes presentados en su trabajo. No obstante, la investigadora afirma que, aunque algunos escritores son cuidadosos y profundos al abordar temáticas raciales y otros alcanzan un entendimiento superficial sobre estos temas, sus trabajos por igual incentivan nuevas formas de pensar sobre la raza para crear una nueva conciencia y para convertir al público en mejores seres humanos.

A pesar de las limitaciones y las controversias, escribir sobre raza tiene gran relevancia porque muestra diferentes perspectivas sobre el racismo que pueden no ser muy evidentes para los miembros de la audiencia. Además, la divulgación actual y precisa de las maquinaciones del poder reduce su eficacia para normalizarse y reforzarse. Por otra parte, el hecho de que los escritores se sientan motivados a escribir sobre temáticas raciales posibilita 
sensibilizar al lector sobre el tema y estimula el análisis profundo y el debate del texto escrito.

El pasado y la historia continúan siendo una fuente de inspiración estimulante para los escritores de este siglo. Ubicada en el contexto de los Derechos Civiles y con una autora blanca escribiendo sobre sobre mujeres negras, The Help generó gran controversia desde su publicación en 2009. Las protagonistas son una joven blanca (Skeeter) y dos criadas negras (Aibileen and Minny) que se unen para denunciar la discriminación sufrida por las domésticas a principios de los años 60 en Mississippi, uno de los estados más segregacionistas en los Estados Unidos. Esta novela ocupó un lugar en la lista de los libros más vendidos del New York Times durante dos años (Smith, 2014) y recibió críticas y halagos de tanto de las audiencias como de intelectuales. Por ese motivo The Help ha sido seleccionada con el objetivo de determinar cómo el discurso de actantes ilocutivos, sujetos valoradores femeninos negros, refleja el imaginario racial del sujeto de la enunciación.

\section{MATERIALES Y MÉTODOS}

La actividad discursiva es una actividad consciente y orientada hacia un objetivo. Tiene un contenido intencional que puede ser expresado mediante enunciados que están formados por uno o más actos de habla. En esta investigación el enunciado es la unidad principal de análisis, aunque con el propósito de profundizar y enriquecer el estudio se analizaron los actos de habla que componen cada enunciado.

Como metodología de trabajo se realizó un análisis del discurso que al ser interdisciplinario requiere de las siguientes normas indispensables:

- El uso de textos escritos u orales auténticos como fuente de análisis para estu- diar el uso del lenguaje

- La consideración del contexto

- El discurso como práctica de la cognición social de los miembros de un grupo

Se escogió la novela The Help como corpus de esta investigación, principalmente porque la autora utiliza el inglés vernáculo (African American Vernacular English) para ilustrar el habla de los afroamericanos, lenguaje que sería empleado en situaciones reales. Por lo tanto, el corpus está conformado por los enunciados de los agentes ilocutivos de acuerdo con la intención del autor como sujeto de la enunciación.

El contexto de esta obra es el pueblo de Jackson, Mississippi durante la década de 1960. El sujeto de la enunciación nació en esta región y por consiguiente, su experiencia personal relacionada con el lenguaje, la forma de pensar, las estructuras institucionales y la relaciones de poder, sirvió para el desarrollo de la narración.

Los hablantes interactúan como miembros de grupos sociales, culturas e instituciones y su discurso forma parte de las relaciones de poder. The Help tiene tres protagonistas Skeeter, Minny y Aibileen. Las dos últimas son mujeres negras. Esta investigación toma como muestra el discurso de estos sujetos valoradores femeninos negros para analizar la influencia del imaginario racial de la autora en el discurso de estos personajes.

Se seleccionaron enunciados con contenido valorador para la caracterización de los sujetos. Como metodología los enunciados fueron divididos en actos de habla para estudiar las dimensiones gramatical, referencial, ilocutiva y modal.

La modalidad indica la posición subjetiva del sujeto hacia lo que se dice en el discurso, que está relacionado con el aspecto semiótico y los 
recursos lingüísticos seleccionados para la formulación del enunciado (Ayala, 2004). Los estudios de Leandro Caballero sentaron las bases para el análisis de las Categorías Semánticas Modales en la Facultad de Lenguas Extranjeras de la Universidad de La Habana. El Grupo de Estudios Semánticos y de Análisis de Discurso Leandro Caballero ha realizado un estudio profundo de la modalidad y se ha enfocado principalmente en las siguientes categorías semánticas modales: Interés, Lealtad, Afectividad, Certidumbre, Expresividad y Valoración.

Primero se brindó información sobre el sujeto valorador, el contexto en que cada enunciado fue emitido, y finalmente el análisis de cada acto de habla con las conclusiones.

\section{RESULTADOS Y DISCUSIÓN}

El análisis de Minny demostró que este es un personaje que se valora de manera positiva y con seguridad como madre, trabajadora doméstica y miembro de la comunidad. Este es un personaje que ha desarrollado su propia perspectiva sobre los problemas que afectan a los afroamericanos (Constantin Agramonte, 2015). No está involucrado directamente con el Movimiento por los Derechos Civiles, pero sí con la lucha. Minny aplica sus propios estándares de pensamiento y acción para retar la ideología dominante, defiende sus principios y no duda al emitir valoraciones negativas hacia lo que ella considera que es incorrecto. Estos resultados evidenciaron la presencia de uno de los temas recurrentes en el pensamiento feminista negro: la afirmación de autodefiniciones y autovaloraciones. Por consiguiente, las apreciaciones sobre la valía personal y la imagen también son brindadas por personajes negros de esta novela y contribuyen a su redondez.

Es un sujeto valorador directo y franco, que no tiene miedo de decir lo que piensa a pesar de las consecuencias que esa actitud puede provocar. Ella es la madre atenta de cinco niños, que debe además cocinar y limpiar en otros domicilios durante todo el día y por la noche cuidar de su hogar y, durante mucho tiempo, lidiar con su esposo alcohólico. Es miembro activo de la comunidad, participa en las actividades de su iglesia y tiene tiempo para ayudar a sus amigas. Su personaje contradice la imagen racista de que afroamericanos incompetentes y vagos.

Por otra parte, Aibileen es la hija de una empleada doméstica y nieta de una esclava, ella ha criado a 17 niños blancos. En el momento de la historia, se encuentra cuidando a la niña de la familia Leefolt. Su vida ha sido desafortunada, su esposo la abandonó y tiempo después su hijo fallece en un accidente, después de que no quisieran socorrerlo en un hospital para blancos. Después de esa tragedia, la actitud de Aibileen cambia y se convierte en la mediadora que alienta a las otras empleadas domésticas a participar en la escritura del libro de denuncia. Es un personaje dinámico.

En los actos de habla de Aibileen se destacan las categorías semánticas modales de lealtad, certidumbre y expresividad. Aibileen es mayormente bien intencionada y segura, aunque a veces puede mostrar indecisión. $\mathrm{Su}$ expresividad es contenida, pero en algunos momentos puede llegar a ser no contenida, e incluso desbordada. Ella muestra su decepción, insatisfacción, pesimismo y miedo. Aunque ella no enfrenta directamente a sus empleadores, Aibileen utiliza otros métodos de resistencia para ayudar a sus amigos. Sus enunciados evidencian la existencia de una doble conciencia. Además, utiliza sus experiencias dolorosas para enfrentar los obstáculos en su vida. Por lo tanto, su historia se desarrolla en el nivel de biografía per 
sonal, considerado por el feminismo negro como sitio de dominación y de resistencia.

No obstante, el estudio del imaginario racial ayudó a vislumbrar la presencia actos de habla valoradores que no eran consistentes con valoraciones previas de Aibileen, que puede ser resultado de los prejuicios o falta de profundización de la autora.

Como cuidadora, este personaje le ha enseñado Mae Mobley, la niña que atiende en esos momentos, a respetar y quererse a sí misma y los demás. Aibileen le ha hablado de personalidades importantes de la lucha afroamericana como Martin Luther King. Sin embargo, cuando se encuentra con uno de sus antiguos niños, que ya ha crecido, ella recuerda lo que le decía de pequeño: "And how I told him don't drink coffee or he gone turn colored. He say he still ain't drunk a cup a coffee and he twenty-one years old. It's always nice seeing the kids grown up fine" (Stockett, 2009, p. 106).

En este enunciado existe una relación causa-efecto. Como Aibileen no quería que el niño bebiera café, lo asustó con la posibilidad de convertirse en negro al hacerlo. Al jugar con la imaginación del niño de esta manera, le atribuye una connotación negativa al hecho de ser negro. El modelo mental de lo negro como una condición mala se ve reforzado por la acción de no tomar café. De esta forma el sujeto valorador brinda apreciaciones negativas de estas dos cuestiones. Al encontrarse con este joven, ya adulto, ella confirma que su método funcionó puesto que él le confiesa que en sus 21 años jamás ha probado esa bebida. Entonces en el último acto de habla de ese enunciado, el sujeto valorador emite una evaluación cualitativa positiva sobre su método de enseñanza al emplear los adjetivos "nice" y "fine".

La relación establecida entre ser negro y to- mar café está presente en otras culturas también. No obstante, este enunciado es evidencia del prejuicio que resulta de la visión hegemónica de la raza y se convierte en un problema ideológico que carga de racismo el discurso de Aibileen y contradice enunciados emitidos por el mismo sujeto valorador sobre este tema. Este ejemplo en la obra sirve de confirmación de lo que han criticado miembros de la comunidad afroamericana sobre este libro: aunque su intención es defender la igualdad, la autora fortalece algunos prejuicios racistas y estereotipos sobre las personas negras.

\section{RESULTADOS Y DISCUSIÓN}

El contexto socio-histórico en el cual la novela fue publicada puede haber contribuido a su éxito controversial. La primera década del siglo XXI estuvo caracterizada por debates sobre lo que representaba ser un ciudadano estadounidense. Durante los primeros ocho años las guerras y la depresión económica provocaron el descontento de gran parte de la población y llenaron de pesimismo a los electores. Esta situación tuvo un gran impacto en la campaña presidencial de 2008 . La victoria de la campaña de Obama basada en la unidad y el optimismo fue interpretada por muchos como el fin del racismo en los Estados Unidos. Varios intelectuales consideraron este momento como el inicio de una era post-racial en el país (Richomme, 2012).

Esta visión post-racial imposibilitó un proceso verdadero por el reconocimiento y el respeto de la diversidad y tuvo un impacto en los medios masivos y el retrato de las relaciones raciales en la pantalla y la literatura. Por lo tanto, este contexto y sus antecedentes pueden haber tenido gran influencia en la redacción y recepción de esta novela que luego se convertiría en película. Esta obra se puede clasificar principalmen- 
te como una novela histórica con algunos rasgos sentimentales. Sin embargo, a pesar de los obstáculos para escribir personajes negros que afectó el reflejo de su identidad, según Greve (2016), la obra de Stockett presenta elementos que son comunes en las novelas afroamericanas como El color púrpura.

La hermandad y la unidad entre mujeres son características presentes en The Help. Sin el vínculo creado por las tres protagonistas, el mensaje de la historia no existiría. A pesar de sus antecedentes diversos, raza y status social, tres mujeres unen fuerzas para denunciar las injusticias sufridas por las criadas negras. Juntas enfrentan el peligro que provocan sus acciones, las represalias de la élite blanca y el patriarcado. Gracias a su apoyo mutuo pueden superar sus inseguridades y crecer en el transcurso de la novela. Resulta necesario resaltar que mientras en las novelas afroamericanas esta relación mujerista ocurre solo entre mujeres negras, Stockett propone esta práctica entre mujeres blancas y negras. De esta manera, The Help intenta estimular un acercamiento real entre feministas blancas y negras.

Empero, la novela ha sido acusada de enfocarse en el sacrificio y transformación de la protagonista blanca, con lo cual se reproduce la jerarquía racial y se menosprecia la historia de los que han sido privados de sus derechos. El libro permite que los lectores blancos se sientan identificados con el personaje blanco al sentir que su redención es también suya mientras que la audiencia negra no se siente bien representada (Smith, 2014). Concuerdo con el razonamiento de que al enfocarse en las victorias y sacrificios del personaje blanco se minimizan los logros y retos de los personajes negros en la novela, con lo cual se obtienen respuestas opuestas de los miembros de la audiencia según su ideolo- gía y posición en las relaciones de poder.

Según Bennett and Royle (2014), existen comunidades de lectores, y los individuos leerán según las convenciones de su comunidad interpretativa. Esa respuesta va a estar determinada por las convenciones de lectura en las cuales ellos han sido educados dentro de un contextos socio-histórico específico. Entonces, la exactitud de esta crítica depende en gran medida del pensamiento crítico del lector y de la comunidad interpretativa en un contexto socio-histórico dado.

Greve afirma que la autora fracasó en el intento de dar profundidad a los personajes negros femeninos. Plantea que cuando surgen preguntas de autoestima y de imagen corporal solo existe respuesta desde la perspectiva de la protagonista blanca y las negras solo existen como víctimas y no como heroínas (Greve, 2016, p.60).

Sin embargo, el análisis dimensional del discurso de Minny demostraró que este sujeto valorador femenino tiene sus propios estándares de belleza y piensa según su experiencia de vida. Minny rechaza ser tratada como un objeto y se reafirma continuamente como una mujer con puntos de vista propios que está dispuesta a expresar abiertamente.

Algunos críticos plantean que The Help enmarcó la desigualdad racial en el contexto de las relaciones interpersonales en vez de la injusticia del sistema. En una declaración abierta de la Asociación de Historiadoras Negras (Association of Black Women Historians), la novela fue desaprobada por brindar poca atención al contexto histórico, con lo 
cual ofreció una imagen reduccionista de las relaciones raciales en ese período y fortaleció los estereotipos racistas como el de la "Big Mama" o la "Mammy", que fueron empleados para humanizar a los blancos liberales (Smith, 2014).

Aunque los personajes negros son sirvientas, ellas desafían el estereotipo de la Mammy. Es cierto que Minny y Aibileen atienden a niños, ancianos y enfermos a su cuidado. No obstante, cuando son maltratadas por sus empleadores, no agachan la cabeza y cada uno de estos personajes encuentra la manera de demostrar su inconformidad y desafiar el status quo.

El personaje de Aibileen es en varios aspectos diferente de Minny. Es una mujer que ha trabajado por más de cuarenta años como doméstica en un ambiente hostil. Ella no es expresiva como Minny ni dice sin tapujos lo que piensa ante sus empleadores. Esta es una mujer que encuentra consuelo en su religión y en la comunidad de su iglesia. Por este motivo ha sido comparada con el Tío Tom. Empero, en el caso de Aibileen se produce un cambio tras la muerte de su hijo, en la cual la discriminación racial jugó un papel relevante. Aibileen se transforma también en una mujer irreprimible que muestra una conformidad aparente mientras esconde su rebeldía y se convierte en la mediadora que alienta a las otras empleadas domésticas a participar en la escritura de un libro de denuncia. Se prueba de esta manera que es un personaje dinámico. Para comprender a profundidad el personaje fue preciso realizar un análisis crítico de su discurso para revelar sus pensamientos de resistencia bajo la superficie. En la investigación realizada se demostró mediante un análisis dimensional cómo el personaje demostraba conformidad en la estructura de superficie y resistencia en la estructura profunda de su discurso.

Como se planteó anteriormente, The Help fue el resultado de la experiencia previa de la autora al haber sido criada por una empleada doméstica afroamericana. En ese sentido la novela es personal, es ficción surgida de los recuerdos de una relación íntima de la autora. Entonces, para mostrar la relación de las criadas entre ellas, con los niños que debían cuidar y con sus empleadores, la selección del espacio doméstico parece válida. Además, como la narrativa principalmente se enfoca en la experiencia de sirvientes afroamericanos, la novela enfatiza las formas en que la supremacía blanca se ejerce en este medio. Como consecuencia, los personajes no están directamente involucrados en el activismo político de la época y la novela carece de intensidad en ese sentido. Sin embargo, el contexto del periodo histórico y los eventos políticos tienen un gran impacto en los personajes y condicionan sus reacciones y actitudes durante el transcurso de la historia.

\section{CONCLUSIONES}

La descripción del "otro" y el imaginario racial todavía continúan siendo objeto de debate mundial y de manera especial, en los Estados Unidos donde bajo la administración de Trump han aumentado los crímenes contra la comunidad negra a manos de la policía, situación que indica la perpetuación de prejuicios y estereotipos en esta sociedad.

Los trabajos literarios son fragmentos de la realidad moldeados por la ideología y 
visión del mundo de los autores y esta perspectiva podrá ser aceptada o rechazada por los lectores. En el discurso literario los escritores como sujetos de la enunciación utilizan a los personajes como agentes ilocutivos para expresar sus valoraciones. Por lo tanto, resulta controversial cuando los autores de una comunidad deciden escribir personajes que pertenecen a otra.

Con esta investigación se pudo demostrar que, aunque la novela The Help tiene aspectos positivos e intenta transmitir un mensaje de diálogo y colaboración, el imaginario racial de la autora como sujeto de la enunciación tuvo una gran influencia en la creación y credibilidad de los personajes.

\section{REFERENCIAS BIBLIOGRAFÍCAS}

Ambriz-Arévalo, G. (junio de 2015). La ideología en Marx: más allá de la falsa conciencia. Pensamiento y Cultura, Vol 18 (1), ISSN: 20275331, p. 107-131. DOI:10.5294/pecu.2015.18.14

Ayala, I.M. (2004) A Characterization of the Feminine Valuating Subject in Alice Walker's Stories. Unpublished doctoral thesis. University of Havana, School of Foreign Languages.

Bennett, A., \& Royle, N. (2014). Literature, criticism and theory (4th ed.). London: Routledge.

Brown, D. \& Webb, C. (2007). Race in the American South, from slavery to Civil Rights. Edinburgh: Edinburgh University Press.

Cabrera, D. H. (2004). Imaginario social, comunicación e identidad colectiva. Consultado el 2 de julio de 2018 en https:// portalcomunicación.com/dialeg/paper/pdf/143_cabrera.pdf
Constantin Agramonte, R.M. (2015). A First Approach to Critical Discourse Analysis of Some Speech Acts of the Novel The Help by Kathryn Stockett. Unpublished term paper, University of Havana, Havana.

Constantin Agramonte, R.M. (2016). Characterization of Minny as a Valuating Subject in the Novel The Help, Written by Kathryn Stockett. Unpublished term paper, University of Havana, Havana.

Constantin Agramonte, R.M. (2017). Racial imaginary in The Help. The intersection of race and gender: Aibileen as valuating subject. Trabajo de diploma, Universidad de La Habana.

Curbeira, A. (2003). Lecturas de Semántica I. La Habana: Editorial Félix Varela.

Foucault, M. (1970). L'ordre du discours. Paris: Éditions Gallimard.

Foucault, M. (1977). Discipline and Punish: The Birth of the Prison. London: Allen Lane.

Gaceta Sanitaria (2010). Imagino colectivo. Imaginario: Teorías 24(5), p.443. Consulado el 6 de junio de 2018 en http://www.scielo. isciii.es/scielo.php?script $=$ sci_arttex\&pid=so213-9111201000500015

Greve, N. L. (2016). Characteristics of African-American literature in Kathryn Stockett's The Help and Alice Walker's The Color Purple. Unpublished master's thesis, University of Alicante, Alicante.

Hart, H. (2004). Sentimental spectacles: the s- 
entimental novel, natural language and early film performance. Unpublished doctoral dissertation, University of Oregon, Oregon.

Hill Collins, P. (1990). Black Feminist Thought: Knowledge, Consciousness, and the Politics of Empowerment. New York: Routledge.

Hill Collins, P. (1992). Race, Class, and Gender: An Anthology. Belmont, CA: Wadsworth Publishing Co.

Hill Collins, P. (2000). Black feminist thought:

Knowledge, consciousness, and the politics of empowerment (2nd edition). London: Routledge.

Hooks, B. (1981). Ain't I a woman: black women and feminism. New York: Routledge.

King, D. (2002). Black Women And Feminism. Women's Studies Encyclopedia.

Retrieved March 11, 2015, from

http://www.gem.greenwood.com/wse/wse.jsp.

Lindón, A. (2007). ¿Qué son los imaginarios y cómo actúan en la ciudad? Entrevista con Nestor García Canclini. Eure. 23 de febrero de 2003. Consultado el 8 de Julio de 2018 en https://www.redalyc.org/pf/196/19609908-pdf

Llewellyn, C. (2015). What we could do with writing. In Rankine, C., Loffreda, B., \& Cap, M. K. (Eds.). The racial imaginary: writers on race in the life of the mind (pp. 43-48). New York: Fence Book.

Loffreda, B., \& Rankine, C., (2015). Introduction. In Rankine, C., Loffreda, B.,\& Cap, M. K. (Eds.). The racial imaginary: writers on race in the life of the mind (pp. 13-22). New York: Fence Book.

Morris, C. \& Nerlich, B. (23 de abril de 2015). Imagining Imaginaries. Blog. University of Nottingham. Consultado el 6 de septiembre de 2018 en http://blogs.nottingham.ac.uk/makingsciencepublic/2015/04/23/ imagining-imaginaries/

Paltridge, B. (2015). Discourse Analysis (2nd ed.). London: Bloomsbury.

Phillips, N.\&Hardy,C.(2002).DiscourseAnalysis. Investigating processes of social construction. California: Sage Publications International Educational and Professional Publisher.

Rankine, C., Loffreda, B., \& Cap, M. K. (Eds.).(2015). The racial imaginary: writers on raceinthelifeofthemind.New York:FenceBook.

Richomme, O. (2012). The post-racial illusion: racial politics an inequality in the age of Obama. Consultado el 12 de julio de 2016 en http://journals.openedition.org/464

Salgado, A. (2009). Holden Caulfield's Valuative Discourse: A First Approximation. Diploma Paper, University of Havana.

Smith, V. (2014). Black women's memories and The Help. Southern Cultures, Spring 2014.

Stockett, K. (2009). The Help. New York: The Berkley Publishing Group.

Van Dijk, T.A. (1993). Principles of critical discourse analysis. Discourse \& Society, 4(2), 249--283. 
Van Dijk, T.A. (1998) Ideology. A Multidisciplinary Approach. London: Sage.

Van Dijk, T.A. (1999). El análisis crítico del discurso. Anthropos, 186(5), 23--36.

Van Dijk, T. A. (2004, mayo). Critical Context Studies. Ponencia presentada en el Congreso de Análisis Crítico del Discurso, Valencia, España.

Walker, A. (1983). In Search of Our Mother's Gadens. Florida: HBJ.

White, D. G. (1999). Ar'n't I a woman? Female slaves in the plantation in the South. New York: W.W. Norton \& Company.

Wodak, R. (2001). Methods of Critical Discourse Analysis. London: Sage.

Wodak, R. \& Mayer, M. (2002). Introducing qualitative methods: methods of Critical Discourse Analysis. London: Sage.
Wodak, R. \& Meyer, M. (2008). Critical Discourse Analysis: history, agenda, theory, and methodology. London: Sage.

Wodak, R.\& Chilton, P. (Eds.). (2005). A new agenda in Critical Discourse Analysis: discourse approaches to politics, society, and culture. Amsterdam: John Benjamins Publishing Company.

Wong, A. (2014). Women raise their voices: $A$ literary analysis of the novel The Help by $\mathrm{Ka}$ thryn Stockett. Unpublished term paper, University of Havana, Havana.

Wong, A. (2015). Breaking the statu quo in the novel The Help. Unpublished diploma paper, University of Havana, Havana. 